Plant Tissue Cult. \& Biotech. 22(1): 65-71, 2012 (June)

$\overline{\mathrm{PTC} \& \mathrm{~B}}$

\title{
Genetic Analysis of Aromatic and Quality Rice Germplasm using Microsatellite Markers
}

\author{
F.D. Shams, M.M.A. Kuddus, K.M. Nasiruddin, S.N. Begum ${ }^{1}$ and \\ M.M. Islam ${ }^{1}$ \\ Department of Biotechnology, Bangladesh Agricultural University, Mymensingh-2202, \\ Bangladesh
}

Key words: Aromatic rice, Grain quality, Microsatellite marker

\begin{abstract}
Twenty rice genotypes were analysed with three SSR primers viz., RM223, RM515 and RM342 for detection of the fgr gene responsible for aroma. The primers RM223 and RM515 identified eight and seven genotypes, respectively as having the fgr locus. Presence of the specific allele of the RM342 amplicon, also correlated with strong aroma in two and with weak aroma in five genotypes. The banding pattern for the primer RM342 was different in genotypes with no aroma. Among the three primers (RM223, RM515 and RM342), RM223 detected the highest number of $f g r$ loci in the 20 rice genotypes. In total 11 genotypes were identified as having strong aroma genes by the three primers. These accessions also showed high yields and therefore may prove to be a good source for producing aromatic rice.
\end{abstract}

\section{Introduction}

Rice (Oryza sativa L.) is the most important crop at the global level, as it is the staple food for more than two-fifths (2.4 billion) of the world's population (Latha et al. 2004). Bangladesh is the fourth largest producer and consumer of rice. It provides about $75 \%$ of the total calories and $55 \%$ of the proteins in the average daily diet of the people of Bangladesh (Bhuiyan and Karim 2002). In Bangladesh, more than 150 crops are grown. Among these, rice occupies about $70 \%$ of the total cultivated area, of which aromatic rice is cultivated roughly in less than $10 \%$ land (Sarker 2002).

Juliano and Duff (1991) reported that grain quality is second after yield as the major breeding objective. Most of the scented rice varieties in Bangladesh are

1Plant Breeding Division, Bangladesh Institute of Nuclear Agriculture, Mymensingh-2202, Bangladesh. 
of traditional type, photoperiod sensitive and cultivated during the Aman season. Majority of these indigenous aromatic rice cultivars are low yielding but its higher price and low cost of cultivation generate higher profit margins compared to other varieties (Kibria et al. 2008). Aroma development is influenced by both genetic and environmental factors. Aroma is best developed when aromatic rice is grown in areas where temperature is cooler during maturity. The biochemical basis of aroma was identified as the presence of 2-acetyl-1-pyrroline (Buttery et al. 1983, Tanchotikul and Hsieh 1991). The conventional methods of plant selection for aroma are not easy because of the large effects of the environment and the low narrow sense heritability of aroma. Recently molecular markers, such as SNPs and simple sequence repeats (SSRs) genetically linked to fragrance have been identified and have the advantage of being inexpensive, simple, rapid and only requiring small amounts of tissue, have been developed for the selection of fragrant rice. Kibria et al. 2008 have used three SSR markers (RM223, RM342 and RM515) for screening of aromatic rice. The present experiment was carried out to select rice genotypes having aroma with fine grain and considerable seed yield. Microsatellite (SSR) markers were employed particularly for genotype selection.

\section{Materials and Methods}

Twenty rice germplasms with diverse origin were used in the present experiment. The origin of these germplasms was not Bangladesh. But these germplasms were available in Bangladesh and for this reason these were included in the present study. The germplasms under study were collected from International Network for Genetic Evaluation of Rice (INGER), IRRI, Philippines.

DNA was extracted from the leaves of each genotype using the CTAB miniprep method (Stewart and Laura 1993) at Biotechnology laboratory, BINA, Mymensingh. The quality of the isolated DNA following this protocol was sufficient for PCR analysis.

RM223, RM342 and RM515 were used to detect marker gene for aroma. These primers were used earlier by Begum (2006) for tagging the genes controlling grain quality traits and RM223 was found closely linked to extremely aromatic phenotypes (Lang and Buu 2008). The details of the primers are given in Table 1. The PCR reaction mixture contained $2 \mu \mathrm{l}$ of $50 \mathrm{ng} / \mu \mathrm{l}$ template DNA,

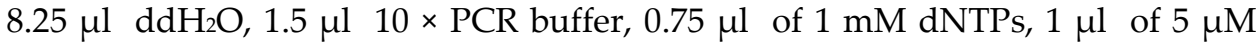
forward and reverse primers and $0.5 \mu \mathrm{l}$ Taq polymerase $(\sim 2.5$ units/ $\mu \mathrm{l})$. Template DNA was initially denatured at $94^{\circ} \mathrm{C}$ for $5 \mathrm{~min}$ followed by 30 cycles of PCR amplification following: $30 \mathrm{sec}$ of denaturation at $94^{\circ} \mathrm{C}, 30 \mathrm{sec}$ of primer annealing at $55^{\circ} \mathrm{C}$ and $1 \mathrm{~min}$ of primer extension at $72^{\circ} \mathrm{C}$. Final 5 min incubation 
at $72^{\circ} \mathrm{C}$ was allowed for complete of primer extension. The amplified products were electrophoretically resolved on a $1.5 \%$ agarose gel in $0.5 \times \mathrm{TBE}$ and visualized under UV light after staining with ethidium bromide. The bands representing particular alleles at the microsatellite loci were scored manually on the basis of parental bands like aromatic type band (Basmati 370), non-aromatic type (IR70) and heterozygotes type band (both).

Table 1. List of selected SSR markers used for grain quality traits.

\begin{tabular}{|c|c|c|c|c|c|c|}
\hline Primer & $\begin{array}{l}\text { Size } \\
\text { (bp) }\end{array}$ & $\begin{array}{c}\text { Chrom. } \\
\text { locus }\end{array}$ & & Sequence & $\begin{array}{l}\text { Annealing } \\
\text { temp. }\left({ }^{\circ} \mathrm{C}\right)\end{array}$ & Reference \\
\hline RM223 & $139-163$ & 8 & $\begin{array}{l}\text { Rev. } \\
\text { Fwd. }\end{array}$ & $\begin{array}{l}\text { GAAGGCAAGTCTTGGCACTG } \\
\text { GAGTGAGCTTGGGCTGAAAC }\end{array}$ & 55 & $\begin{array}{l}\text { Temnykh et al. } \\
2000\end{array}$ \\
\hline RM342 & n.a. & 8 & $\begin{array}{l}\text { Rev. } \\
\text { Fwd. }\end{array}$ & $\begin{array}{l}\text { ACTATGCAGTGGTGTCACCC } \\
\text { ССАТССТССТАСТTCAATGAAG }\end{array}$ & 55 & $\begin{array}{l}\text { Temnykh et al. } \\
2000\end{array}$ \\
\hline RM515 & $205-231$ & 8 & $\begin{array}{l}\text { Rev. } \\
\text { Fwd. }\end{array}$ & $\begin{array}{l}\text { TGGCCTGCTCTСТСТСТСТC } \\
\text { TAGGACGACCAAAGGGTGAG }\end{array}$ & 55 & $\begin{array}{l}\text { Temnykh et al } \\
2001\end{array}$ \\
\hline
\end{tabular}

\section{Results and Discussion}

Twenty rice genotypes were analyzed with SSR markers for detection of the fgr gene. For separating of fragrance producing alleles from non-fragrance producing alleles at the fgr locus, the PCR based markers were found to be useful. The primers RM223, RM342 and RM515 were used to identify or detect the presence of quality trait gene aroma, which were used earlier by Garland et al. (2000), Jain et al. (2004), Begum (2006) and Kibria et al. (2008).

In all the 20 germplasms of rice, two alleles were detected at the RM223, RM342 and RM515 locus. All the aromatic genotypes showed alleles like that of Basmati 370. Some of the varieties showed alleles similar to the allele of nonaromatic rice like IET15833 (RP3135-92-1-11-5), IR72 and UPL RI-5.

The genotypes, Basmati 370, IET17278 (RP3641-108-7-5-3), IR78086-15-1-1-35, IR27069-B53-B-B-1-4-4, IR70444 -164-1-2, KHAO-TAH-HAENG 17, WAS 169B-B-4-2-13 and WAS 197-B-4-1-13 were found to have strong aroma; HB-1, IR77542-167-1-1-1-3, IR77542-201-1-1-1-1-4, IR77542-90-1-1-1-1-5, IR70456-75-2-11-2 and IR77542-487-1-1-1-1-2 with moderate aroma; BKNFR76031-1-7-1, SPR86035-52-5-1-1, IR50, IR72, and IET15833(RP3135-92-1-11-5), UPL RI-5 had slight to no aroma (Table 2, Fig. 1a).

A specific allele amplified by the primer RM515 was present in the genotypes Basmati 370, HB-1, IR77542-90-1-1-1-1-5, IR27069-B53-B-B-1-4-4, KHAO-TAH-HAENG 17, UPL RI-5 and WAS 169-B-B-4-2-13. These genotypes also had strong aroma; IR77542-201-1-1-1-1-4, IR70456-75-2-1-1-2, IR77542-487-11-1-1-2, SPR86035-52-5-1-1, WAS 197-B-4-1-13, IR50 had as moderate aroma; 
IR72, BKNFR76031-1-7-1, IET15833(RP3135-92-1-11-5), IET17278 (RP3641-108-7-53), IR77542-167-1-1-1-3, IR78086-15-1-1-3-5, IR70444 -164-1-2 had slight to no aroma (Table 2, Fig. 1b).

Table 2. Genetic analysis of 20 rice germplasms with grain yield.

\begin{tabular}{|c|c|c|c|c|}
\hline \multirow{2}{*}{ Varieties } & \multirow{2}{*}{$\begin{array}{c}\text { Grain yield/ } \\
\text { plant }(\mathrm{g})\end{array}$} & \multicolumn{3}{|c|}{ Genotype analysis } \\
\hline & & RM223 & RM515 & RM342 \\
\hline BKNFR 76031-1-7-1 & 18.23 & -- -- & -- -- & * \\
\hline HB-1 & 13.11 & +-- & ++ & * \\
\hline IET15833 (RP3135-92-1-11-5) & 20.96 & -- -- & -- & * \\
\hline IET17278(RP3641-108-7-5-3) & 19.01 & ++ & --- & * \\
\hline IR77542-167-1-1-1-3 & 24.76 & +-- & -- -- & * \\
\hline IR77542-201-1-1-1-1-4 & 14.01 & +-- & +-- & * \\
\hline IR77542-90-1-1-1-1-5 & 22.29 & +-- & ++ & -- -- \\
\hline IR78086-15-1-1-3-5 & 23.77 & ++ & -- -- & * \\
\hline IR27069-B53-B-B-1-4-4 & 20.57 & ++ & ++ & * \\
\hline IR70444-164-1-2 & 16.36 & ++ & -- -- & * \\
\hline IR70456-75-2-1-1-2 & 18.37 & +-- & +-- & * \\
\hline IR77542-487-1-1-1-1-2 & 17.65 & +-- & +-- & -- -- \\
\hline KHAO-TAH-HAENG 17 & 14.00 & ++ & ++ & ++ \\
\hline SPR86035-52-5-1-1 & 19.09 & -- -- & +-- & * \\
\hline UPL RI-5 & 21.77 & -- -- & ++ & * \\
\hline WAS 169-B-B-4-2-13 & 21.03 & ++ & ++ & -- -- \\
\hline WAS 197-B-4-1-13 & 17.84 & ++ & +-- & $*$ \\
\hline Basmati 370 & 16.67 & ++ & ++ & ++ \\
\hline IR50 & 17.34 & -- -- & +-- & -- -- \\
\hline IR72 & 15.64 & -- -- & -- -- & -- -- \\
\hline
\end{tabular}

$++=$ Strong aroma. -- -- = Slight to no aroma. + -- = Moderate aroma. ${ }^{*}=$ Polymorphic.

Specific alleles of RM342, was found in the genotype Basmati 370 and KHAO-TAH-HAENG 17 which also had strong aroma. On the other hand IR72, IR77542-90-1-1-1-1-5, IR77542-487-1-1-1-1-2, WAS 169-B-B-4-2-13 and IR50 were found to have slight to no aroma. The banding pattern for the primer RM342 was different than rest of the germplasms. The alleles responsible for aroma showed polymorphism. This polymorphism resulted in different banding patterns. The variabilities in the patterns of bands might be due to the presence of some other volatile compounds in alleles which are responsible for aroma. The banding pattern for the primer RM342 is presented in Table 2, Fig. 1c).

Among the three primers (RM223, RM515, RM342), RM223 detected highest number of $f g r$ locus Table 2, Fig. 1a. 
Grain yield per plant ranged from 14.00 to $24.76 \mathrm{~g}$. Among the germplasm, IR77542-167-1-1-1-3 produced the highest yield whereas KHAO-TAH-HAENG 17 produced the lowest yield (Table 2 ).

\section{$\begin{array}{llllllllllllllllllllll}1 & 2 & 3 & 4 & 5 & 6 & 7 & 8 & 9 & 10 & 11 & 12 & 13 & 14 & 15 & 16 & 17 & 18 & 19 & 20 & 21 & 22\end{array}$}

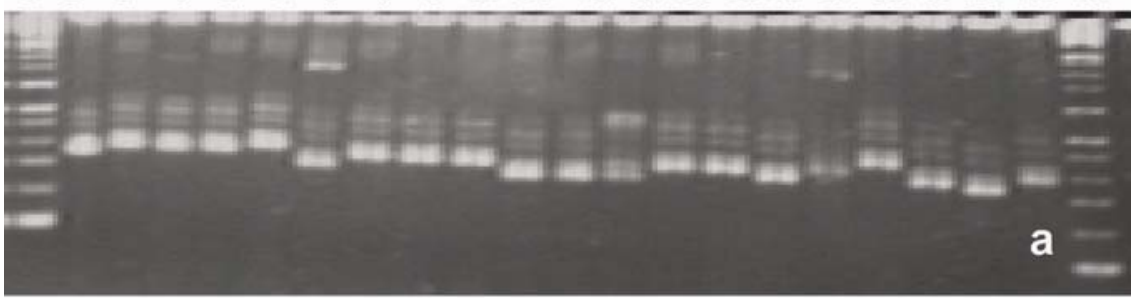

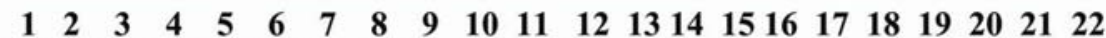

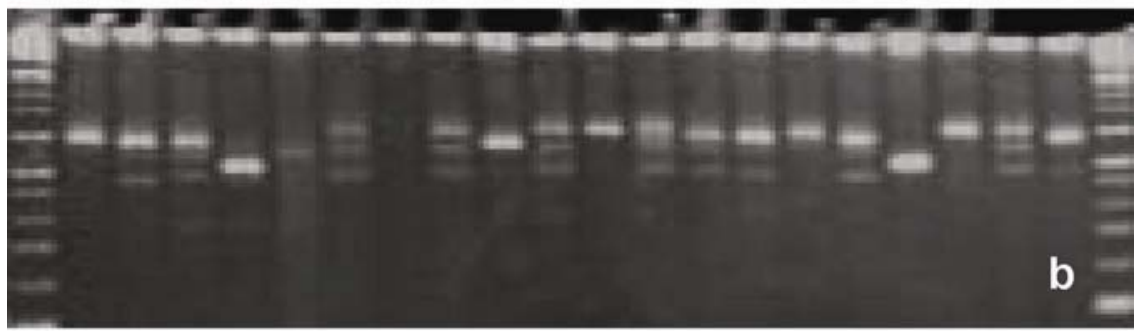

$\begin{array}{llllllllllllllllllllll}1 & 2 & 3 & 4 & 5 & 6 & 7 & 8 & 9 & 10 & 11 & 12 & 13 & 14 & 15 & 16 & 17 & 18 & 19 & 20 & 21 & 22\end{array}$

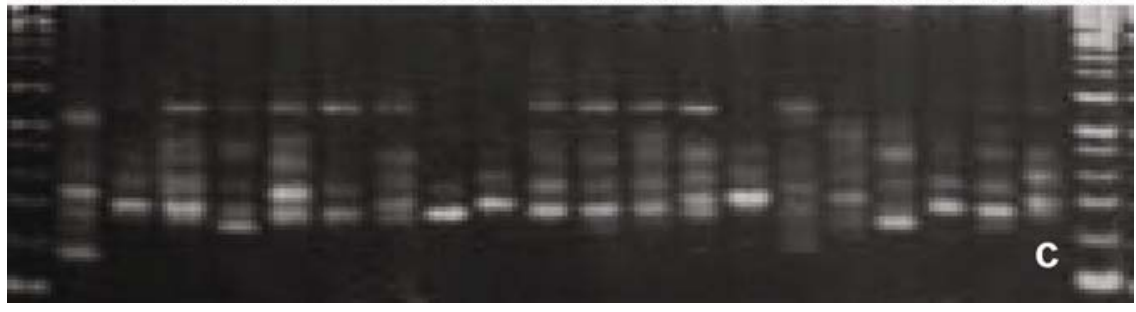

Fig. 1. Banding pattern of 20 rice germplasm using RM223 (a), RM515 (b), RM342 (c) Lane-1 and Lane-22: 20 bp ladder; Lane-2: Basmati 370; Lane-3:IR72; Lane-4: BKNFR76031-1-7-15; Lane-5: HB1; Lane-6: IET15833 (RP3135-92-1-11-5); Lane-7: IET17278(RP3641-108-7-5-3); Lane-8: IR77542-1671-1-1-3; Lane-9: IR77542-201-1-1-1-1-4; Lane-10: IR77542-90-1-1-1-1-5; Lane-11: IR78086-15-1-1-3-5; Lane12: IR27069-B53-B-B-1-4-4; Lane-13: IR70444 -164-1-2; Lane-14: IR70456-75-2-1-1-2; Lane-15: IR77542-487-1-1-1-1-2; Lane-16 : KHAO-TAH-HAENG 17; Lane-17: SPR86035-52-5-1-1; Lane-18: UPL RI-5; Lane-19: WAS 169-B-B-4-2-13; Lane-20: WAS 197-B-4-1-13; Lane-21: IR50.

Jain et al. (2004) reported that SSRs (RM342, RM42, RM223) showed a high degree of polymorphism between Basmati and non-Basmati type aromatic rice. Begum (2006) reported that three markers RM223, RM342 and RM515 located on chromosome 8 , were found to be strongly associated $(\mathrm{p}<0.0001)$ with aroma and explained 22.46, 28.38 and $41.78 \%$ of the total phenotypic variation. After genotypic observation, it was found that among the three primers, RM223 responded best in all the 20 rice genotypes because RM223 primer could identify 
aromatic and non-aromatic germplasm effectively which supported the phenotypic result.

In the light of the above discussion microsattelite has been shown to be appropriate as markers to evaluate the genetic variation among the rice germplasms. The germplasms that are used here have the potential to improve breeding programs for release of a new aromatic rice variety with better agronomic performance and better aroma.

\section{Acknowledgements}

Authors are grateful to Bangladesh Institute of Nuclear Agriculture (BINA) authorities for providing the rice germplasms for this investigation.

\section{References}

Begum SN (2006) Development of Basmati-derived rice lines for grain quality and resistance to bacterial blight. Ph. D. Thesis. Bangladesh Agricultural University, Mymensingh, Bangladesh. p. 215.

Bhuiyan SI and Karim ANMR (2002) Rice production in Bangladesh: An overview. Bangladesh Rice Research Institute. Joydebpur, Dhaka. pp. 13-17.

Buttery RG, Ling LC, Juliano BO and Turnbaugh J (1983) Cooked rice aroma and 2-acetyl-1-pyrroline. J. Agric. Food Chem. 31: 823-826.

Garland S, Lewin L, Blakeney A, Reinke R and Henry R (2000) PCR-based molecular markers for the fragrance gene in rice (Oryza sativa L.). Theor. Appl. Genet. 101: 364-371.

Jain S, Jain RK and McCouch SR (2004) Genetic analysis of Indian aromatic and quality rice (Oryza sativa L.) germplasm panels of fluorescently labeled microsatellite markers. Theor. Appl. Genet. 109(5): 965-977.

Juliano BO and Duff B (1991) Rice grain quality as an emerging priority in National rice breeding programmes. In: Rice grain marketing and quality issues. Los Banos, Laguna, IRRI. pp. 55-64.

Kibria K, Islam MM and Begum SN (2008) Screening of aromatic rice lines by phenotypic and molecular marker. Bangladesh J. Bot. 37(2): 141-147.

Lang TN and Buu CB (2008) Development of PCR-based markers for aroma (fgr) gene in rice (Oryza sativaI L.) Omonrice 16: 16-23.

Latha R, Rao CS, Subramanian HMS, Eganathan P and Swaminathan MS (2004) Approaches to breeding for salinity tolerance - A case study on Proterena coarctata. Ann. Appl. Biol. 144(2): 177-184.

Sarker MAH (2002) Indigenous fine aromatic rice production: Bangladesh perspective. 12-15 November 2002. Development of basic standard for organic rice cultivation RDA/ARNOA international conference. RDA and Dankook Univ., Korea.

Stewart NC Jr. and Laura E (1993) A Rapid CTAB DNA Isolation Technique Useful for RAPD Fingerprinting and Other PCR Applications. BioTechniques.14(5):748-749. 
Tanchotikul U and Hsieh TCY (1991) An improved method for quantification of 2-acetyl1-pyrroline a popcorn-like aroma, in aromatic rice by high-resolution gas chromatography/mass chromatography/selected ion monitoring. J. Agric. Food Chem. 39: 944-947.

Temnykh S, Park WD, Ayres N, Cartinhour S, Hauck N, Lipovich L, Cho YG, Ishii T and McCouch SR (2000) Mapping and genome organization of microsatellite sequences in rice (Oryza sativa L.). Theor. Appl. Genet. 100: 697-712.

Temnykh, S, DeClerck G, Lukashova A, Lipovich L, Cartinhour S and McCouch SR (2001) Computational and experimental analysis of microsatellites in rice (Oryza sativa L.): Frequency, length variation, transposon associations, and genetic marker potential. Genome Res. 11: 1441-1452. 